\title{
Volatiles in Distillates of Cider Aged in American Oak Wood
}

\author{
J uan Mangas, ${ }^{*},{ }^{\dagger}$ Roberto Rodríguez, ${ }^{\dagger}$ J avier Moreno, ${ }^{\dagger}$ and Domingo Blanco ${ }^{\ddagger}$ \\ Instituto de Experimentación y Promoción Agraria, Apartado 13, E-33300 Villaviciosa-Asturias, Spain, and \\ Departamento de Química Física y Analítica, Universidad de Oviedo, E-33006 Oviedo, Spain
}

\begin{abstract}
A fast, reliable method is described for determining volatile components in distillates of different kinds of cider aged in oak wood. During aging, a significant increase was detected in the concentration of diethyl butanedioate, ethyl 3-methylbutanoate, esters of long-chain fatty acids, and 1-hexanol; in contrast, the acetate esters and long-chain fatty acids decreased. When cider made with traditional technology was used as raw material, spirits with higher concentrations of decanoic and dodecanoic ethyl esters and long-chain fatty acids were obtained. When cluster and factor analyses were empl oyed, "natural" groupings among the spirits studied were obtained on the basis of the raw material used and aging time.
\end{abstract}

Keywords: Volatile compounds; cider brandy; GC-MS

\section{INTRODUCTION}

It is well-known that the flavor of spirits aged in wood is based on a number of compounds such as carbonyls, alcohols, esters, lactones, acetals, polyphenols, acids, carbohydrates, steroids, nitrogenous and sulphurcontaining compounds, microelements, and other substances of a miscellaneous nature (Black and Andreasen, 1973; De Smedt and Liddle, 1978; Guymon and Crowell, 1972; Nykanen and Suomalainen, 1972; Loyola et al., 1990; Williams and Strauss, 1975; Herraiz et al., 1990; Lehtonen and Suomalainen, 1977; Yavas and Rapp, 1991). The flavor of unaged spirits and spirits aged in wood comes from each successive stage of the manufacturing process, namely the processing of raw materials, fermentation, distillation, and finally maturation in oak wood.

Obviously, the composition of unaged distillates depends on the nature of the raw material and the distillation technology employed. For example, the quality of the raw material used can be related to the level of 2-propen-1-ol in spirits (De Smedt and Liddle, 1976), the furfural percentage in distillates can be increased if a pot still distillation system is used, and esterification reactions can take place on the plates of continuous stills which must modify the neutral ester composition of unaged distillate (Onishi et al., 1977).

However, the formation of congeners in aged spirits is related to maturation reactions, the chemical processes that involve distillate constituents, and the interactions between the components of both the wood and the distillate (Reazin, 1981). Thus, diethyl butanedioate, 5-methylfurfural, $\beta$-sitosterol, and $\beta$-methyl- $\gamma$ octalactone are components derived from oak (Guymon and Crowell, 1972); likewise, different carbohydrates (arabinose, xylose, galactose, and rhamnose) are produced from maturation reactions. These constituents affect the release of flavor volatiles, since an increase in solubility of ethyl esters (components correlated to immature odors in spirits) has been shown to exist in aged brandy, which corresponds with a reduction in the

* Author to whom correspondence should be addressed

† Instituto de Experimentación y Promoción Agraria.

‡ Universidad de Oviedo. headspace concentration of said esters, and the extraction of wood components during aging (Piggott et al., 1992).

On the other hand, 3,3-diethoxybutan-2-one and 1,1,3triethoxypropane are synthesized from diacetyl and acrolein interaction with ethanol, respectively, and their formation is catalyzed at low pH (Williams and Strauss, 1975); ethanol is transformed into acetaldehyde, acetic acid, and ethyl acetate (Reazin et al., 1976), and the acetate esters of isoamyl, $\mathrm{n}$-hexyl, and $\beta$-phenethyl alcohols decrease during aging (Onishi et al., 1977).

F urthermore, the formation of aromatic al dehydes is based on wood lignin-ethanol interaction and the following oxidation by the molecular oxygen (Reazin, 1981).

Traditionally, the flavor analysis of alcoholic beverages is accomplished by a liquid-liquid extraction method using a low boiling point solvent, following concentration and injection in split technique steps, and finally qualitative and quantitative analysis by GCMS. Trichlorofluoromethane (freon 11) has been proposed as a suitable solvent for extracting aromas in alcoholic beverages (Hardy, 1969; Herraiz et al., 1990; Marais and Houtman, 1979) due to its high efficiency in the extraction of al cohols of $C_{5}$ and above and its low efficiency for $\mathrm{C}_{4}$ and below and its low boiling point (23.8 ${ }^{\circ} \mathrm{C}$ ), which allows an easy concentration step, although occasionally a loss of some volatile compounds may occur, and because it is a noninflammable solvent. Other solvents, such as n-pentane, have al so been used for extracting spirit flavors (Liebich et al., 1970).

On the other hand, a fast microextraction with 1,1,2trichloro-1,2,2-trifluoroethane (freon 113), with a very high sample/solvent ratio (the concentration step is not necessary), which is less polluting and less expensive than liquid-liquid extraction, and with good relative precision (less than 3\%), has been used for analysis of wine flavor compounds (Ferreira et al., 1993).

The aim of this work was to gain an insight into the knowledge of the aroma components in distillates of ciders during aging and to ascertain which of them can be employed for classifying the spirits on the basis of raw material and aging time. With this aim in mind, a microextraction of the aroma components with freon 113 and a GC-MS analysis of these was carried out on cider brandy during 9 months of aging. 


\section{EXPERIMENTAL PROCEDURES}

Raw Material. Two types of cider were used to make spirits: cider produced according to traditional technology $(A)$ and cider obtained from apple juice concentrate (B). The traditional cider was prepared from the juice of a mixture of cider apples with different sensory properties, endowing the resulting juice with an overall acidic nature. The mixture of apples was processed in a pilot plant which included the following steps: milling with a hammer mill and slow pressing with a batch mechanical press ( 4 days of pressing time). The fermentation process was then conducted by wild microflora for 4 months. In the case of the type B cider, a starter of Saccharomyces cerevisiae was employed. The al coholic degrees were $6 \%(\mathrm{v} / \mathrm{v})$ for traditional cider and $8 \%(\mathrm{v} / \mathrm{v})$ for cider made from apple juice concentrate.

Distillation. The batch distillation system for distilling each cider was employed. The copper wash-still distillation vessel capacity was $500 \mathrm{~L}$, and steam was used as heat source. The volatile compounds obtained in the first vessel of the still were carried to the rectifying column, which had 16 bubblecap plates; 1150 and $1760 \mathrm{~L}$ of traditional cider and type B cider, respectively, were employed to make the spirits. The alcoholic degree of the spirits was monitored during the distillation process. Three fractions of spirits, namely, heads, hearts, and tails, were separated on the basis of their alcoholic contents. The volume of heads obtained was $1 \%$ of the volume of the cider employed $(250 \mathrm{~L})$, the average al coholic degrees of the heart fraction were $65 \%(\mathrm{v} / \mathrm{v})$ for distillates obtained from traditional cider and $62 \%(\mathrm{v} / \mathrm{v})$ in the case of the type $\mathrm{B}$ cider; the tails produced (average alcoholic degree, 30\% v/v) were employed in the following distillations. All heart fractions obtained were subjected to an aging process in American oak barrels with $35 \mathrm{~L}$ capacity for 9 months; four samplings (each three months) were carried out. The experiments for the aging of the spirits were performed in triplicate (type B) and duplicate (type A).

Extraction. A microextraction with freon 113 was employed in this study according to the method described by Ferreira (1992). Ten milliliters of spirit, previously diluted to $30 \%(\mathrm{v} / \mathrm{v})$ in ethanol to avoid the formation of three phases, was introduced into the extraction centrifuge tubes jointly with $150 \mu \mathrm{L}$ of freon $113,5 \mu \mathrm{L}$ of a solution of 2-ethyl-1-hexanol ( $13 \mathrm{~g} / \mathrm{L}$ in ethanol at $30 \% \mathrm{v} / \mathrm{v}$ ) as internal standard, and $2 \mathrm{~g}$ of $\left(\mathrm{NH}_{4}\right)_{2} \mathrm{SO}_{4}$. The tubes were then shaken by means of a 1024 water shaking bath (Tecator) at $20{ }^{\circ} \mathrm{C}$ for $1 \mathrm{~h}$ at maximun speed. After this, the tubes were centrifuged $(5000 \mathrm{rpm}$ for $10 \mathrm{~min}$ ); the organic phase was then recovered, and $1 \mu \mathrm{L}$ was injected into the chromatographic system.

Reagents. Standards of analytical quality were supplied by Fluka (Busch, Switzerland) and Sigma-Aldrich (Madrid, Spain). Standard solutions were prepared in $\mathrm{EtOH} /$ water (30/ $70 \mathrm{v} / \mathrm{v})$.

Gas Chromatography-Mass Spectrometry. Gas chromatography-mass spectrometry was performed on a HewlettPackard 5970A mass selective detector (MSD) interfaced with a Hewlett-Packard 5790 gas chromatograph fitted with a column (FFAP, $50 \mathrm{~m} \times 0.22 \mathrm{~mm}$ i.d.; phase thickness, 0.33 $\mu \mathrm{m}$ ) inserted into a split/splitless injector (splitless time, 1 min). Chromatographic conditions were as follows: initial temperature, $40^{\circ} \mathrm{C}$; program rate, $3^{\circ} \mathrm{C} / \mathrm{min}$; final temperature, $220^{\circ} \mathrm{C}$; injector and detector temperature, $250^{\circ} \mathrm{C}$; carrier gas, $\mathrm{He}$ at $1 \mathrm{~mL} / \mathrm{min}$. The analyses were performed in the electron impact $(\mathrm{EI})$ mode, and the ionization vol tage was fixed at 70 eV.

Statistical Analysis. Repeated measures analysis of variance with a Greenhouse-Geisser and Huynh-Feldt fitting was carried out using the SAS (1985) statistical package. The data matrix was analyzed by principal components analysis and cluster analysis (SPSS, 1988).

\section{RESULTS AND DISCUSSION}

Optimization of the Microextraction System. The extraction time $(30,60,120$, and $180 \mathrm{~min})$, salt type $\left[\mathrm{NaH}_{2} \mathrm{PO}_{4}\right.$ and $\left.\left(\mathrm{NH}_{4}\right)_{2} \mathrm{SO}_{4}\right]$, and its concentration $(0,100$, and $200 \mathrm{~g} / \mathrm{L}$ ) were studied by means of treatment of onedimensional data as factors influencing the microextraction process. To avoid the formation of three phases, a concentration of $200 \mathrm{~g} / \mathrm{L}$ of salt was fixed as maximum. The extraction time was fixed at $60 \mathrm{~min}$, since higher values did not give higher extraction levels of the analytes studied (ethyl esters of fatty acids, higher alcohols, fatty acids, and acetate esters). An analysis of variance was carried out to determine if the salt concentration and salt type influenced the extraction of the analytes of interest. Except for 3-methylbutyl ethanoate and ethyl hexanoate, the salt type and its concentration significantly influenced the extraction for all of the compounds studied at a 95\% confidence level. The best microextraction conditions were obtained with $\left(\mathrm{NH}_{4}\right)_{2} \mathrm{SO}_{4}$ at $200 \mathrm{~g} / \mathrm{L}$.

Quantitative Analysis of Aged Spirit Volatiles. The quantification of volatiles was achieved by using the internal standard method, and detection was carried out by single ion monitoring (SI M). The ions employed for the detection of volatiles were as follows: $\mathrm{m} / \mathrm{z} 60$ $\left[\mathrm{C}_{2} \mathrm{H}_{4} \mathrm{O}_{2}\right]^{+}$for fatty acids, $\mathrm{m} / \mathrm{z} 88\left[\mathrm{C}_{4} \mathrm{H}_{8} \mathrm{O}_{2}\right]^{+}$for ethyl esters of fatty acids, and $\mathrm{m} / \mathrm{z}[\mathrm{M}-60]^{+}$for acetate esters, according to the criteria of Woidich et al. (1978); different ions were additionaly chosen in the case of the higher alcohols.

Recovery studies were carried out to determine the accuracy of the method. Known amounts of each volatile compound, namely, fatty acids (octanoic, decanoic, dodecanoic, and tetradecanoic), alcohols (3methyl-1-butanol, 1-hexanol, 1-octanol, and 1-octadecanol), and esters (ethyl 3-methylbutanoate, 3-methylbutyl ethanoate, ethyl hexanoate, ethyl octanoate, ethyl decanoate, ethyl dodecanoate, ethyl tetradecanoate, hexyl ethanoate, diethyl butanodioate, ethyl hexadecanoate, ethyl 9,12-octadecadienoate, and 2-phenylethyl ethanoate), were added to a variety of samples, and the resulting spiked samples were subjected to the entire analytical sequence. All analyses were carried out in triplicate at three concentration levels.

The recovery levels and relative standard deviations for the analytes studied are shown in Table 1 . As can be seen, recoveries ranged between 91 and $114 \%$ for fatty acids, between 83 and $108 \%$ for acetate esters, between 85 and $113 \%$ for ethyl esters of fatty acids, and between 89 and $108 \%$ for higher alcohols, with a relative standard deviation usually smaller than $7.5 \%$, which means that the optimized analytical methodology is suitable for our technological purpose.

Analytical Control of Volatile Components during Aging. Esters of monocarboxylic acids have been regarded as compounds that exert a significant influence on the aroma of distilled beverages. In this study, we have monitored the evolution during aging of different ethyl esters of fatty acids, namely 3-methylbutanoic, hexanoic, octanoic, decanoic, dodecanoic, tetradecanoic, hexadecanoic, and 9,12-octadecadienoic. Ethyl 3-methyl butanoate occurred in concentrations less than 0.10 $\mathrm{mg} / \mathrm{L}$ in all spirits studied, and its concentration increased during aging $(P=0.0019)$. We found the highest level in the case of spirit obtained from cider produced by means of the traditional system $(A)(P=$ $0.0001,0.0076$, and 0.0008 for three aging steps); this component was not detected, however, in the unaged spirit (Table 2). Therefore, it should be included as a minor component of the aged cider distillates, which could exert a significant influence over the spirit aroma 
Table 1. Recovery Studies of Volatile Compounds Added to Distillates of Cider

\begin{tabular}{|c|c|c|c|c|}
\hline compound & $\begin{array}{c}\text { amount in spirit } \\
\text { (mg/L } \pm \text { RSD) }\end{array}$ & $\begin{array}{c}\text { amount } \\
\text { added (mg/L) }\end{array}$ & $\begin{array}{c}\text { found } \\
\text { (mg/L } \pm \text { RSD) }\end{array}$ & $\begin{array}{c}\text { recovery } \\
(\%)\end{array}$ \\
\hline 3-methyl-1-butanol & $1119.86 \pm 5.79$ & $\begin{array}{r}433.47 \\
619.24 \\
1548.10\end{array}$ & $\begin{array}{l}1521.00 \pm 3.96 \\
1738.87 \pm 9.50 \\
2797.44 \pm 4.16\end{array}$ & $\begin{array}{r}92.54 \\
99.96 \\
108.36\end{array}$ \\
\hline 1-hexanol & $36.44 \pm 0.56$ & $\begin{array}{l}12.47 \\
21.83 \\
31.18\end{array}$ & $\begin{array}{l}48.90 \pm 1.19 \\
59.64 \pm 2.01 \\
69.40 \pm 3.06\end{array}$ & $\begin{array}{r}99.92 \\
106.28 \\
105.71\end{array}$ \\
\hline 1-octanol & $0.47 \pm 8.19$ & $\begin{array}{l}0.29 \\
0.50 \\
0.72\end{array}$ & $\begin{array}{l}0.73 \pm 1.52 \\
0.99 \pm 5.58 \\
1.20 \pm 2.23\end{array}$ & $\begin{array}{r}89.65 \\
104.00 \\
101.39\end{array}$ \\
\hline 1-octadecanol & $0.13 \pm 8.00$ & $\begin{array}{l}0.57 \\
0.99 \\
1.42\end{array}$ & $\begin{array}{l}0.71 \pm 8.00 \\
1.18 \pm 7.72 \\
1.53 \pm 7.37\end{array}$ & $\begin{array}{r}101.75 \\
106.06 \\
98.59\end{array}$ \\
\hline octanoic acid & $9.34 \pm 1.95$ & $\begin{array}{r}8.00 \\
24.01 \\
40.02\end{array}$ & $\begin{array}{l}18.53 \pm 1.55 \\
35.57 \pm 2.54 \\
53.78 \pm 1.98\end{array}$ & $\begin{array}{l}114.88 \\
109.24 \\
111.04\end{array}$ \\
\hline decanoic acid & $6.01 \pm 1.85$ & $\begin{array}{r}2.00 \\
6.02 \\
10.03\end{array}$ & $\begin{array}{r}8.04 \pm 1.17 \\
11.50 \pm 2.70 \\
15.29 \pm 3.58\end{array}$ & $\begin{array}{r}101.50 \\
91.20 \\
92.52\end{array}$ \\
\hline tetradecanoic acid & $0.64 \pm 2.94$ & $\begin{array}{l}0.40 \\
1.20 \\
1.99\end{array}$ & $\begin{array}{l}1.07 \pm 3.87 \\
1.74 \pm 4.49 \\
2.50 \pm 3.14\end{array}$ & $\begin{array}{r}107.50 \\
91.67 \\
93.47\end{array}$ \\
\hline ethyl 9,12-octadecadienoate & $2.00 \pm 4.43$ & $\begin{array}{l}1.36 \\
4.09 \\
6.83\end{array}$ & $\begin{array}{l}3.52 \pm 5.06 \\
6.60 \pm 4.61 \\
9.75 \pm 2.39\end{array}$ & $\begin{array}{l}111.76 \\
112.47 \\
113.47\end{array}$ \\
\hline ethyl hexanoate & $2.64 \pm 2.57$ & $\begin{array}{r}1.83 \\
7.33 \\
12.83\end{array}$ & $\begin{array}{r}4.43 \pm 1.10 \\
9.52 \pm 0.43 \\
14.95 \pm 4.97\end{array}$ & $\begin{array}{l}97.81 \\
93.86 \\
95.95\end{array}$ \\
\hline ethyl hexadecanoate & $4.88 \pm 2.78$ & $\begin{array}{r}3.46 \\
6.92 \\
13.84\end{array}$ & $\begin{array}{r}8.00 \pm 1.25 \\
11.04 \pm 8.50 \\
19.09 \pm 3.98\end{array}$ & $\begin{array}{r}90.17 \\
89.01 \\
102.67\end{array}$ \\
\hline diethyl butanedioate & $5.32 \pm 3.43$ & $\begin{array}{l}0.91 \\
3.66 \\
6.41\end{array}$ & $\begin{array}{r}6.18 \pm 1.49 \\
9.20 \pm 2.49 \\
12.10 \pm 3.42\end{array}$ & $\begin{array}{r}94.51 \\
106.01 \\
105.77\end{array}$ \\
\hline hexyl ethanoate & $0.12 \pm 1.35$ & $\begin{array}{l}0.14 \\
0.56 \\
0.98\end{array}$ & $\begin{array}{l}0.24 \pm 1.30 \\
0.62 \pm 1.88 \\
1.00 \pm 3.87\end{array}$ & $\begin{array}{l}85.71 \\
89.29 \\
89.80\end{array}$ \\
\hline 3-methylbutyl ethanoate & $4.13 \pm 4.42$ & $\begin{array}{l}1.72 \\
3.44 \\
5.17\end{array}$ & $\begin{array}{l}5.57 \pm 3.02 \\
7.27 \pm 6.23 \\
8.93 \pm 7.30\end{array}$ & $\begin{array}{l}83.72 \\
91.28 \\
92.84\end{array}$ \\
\hline 2-phenylethyl ethanoate & $0.14 \pm 9.15$ & $\begin{array}{l}0.12 \\
0.49 \\
0.86\end{array}$ & $\begin{array}{l}0.25 \pm 1.86 \\
0.64 \pm 2.78 \\
1.07 \pm 3.81\end{array}$ & $\begin{array}{r}91.67 \\
102.04 \\
108.14\end{array}$ \\
\hline ethyl decanoate & $4.99 \pm 3.52$ & $\begin{array}{l}2.23 \\
6.34 \\
9.45\end{array}$ & $\begin{array}{r}7.34 \pm 2.98 \\
10.65 \pm 2.10 \\
14.08 \pm 1.42\end{array}$ & $\begin{array}{r}105.38 \\
89.27 \\
96.19\end{array}$ \\
\hline ethyl dodecanoate & $3.64 \pm 5.28$ & $\begin{array}{l}3.20 \\
4.60 \\
8.34\end{array}$ & $\begin{array}{r}7.19 \pm 4.36 \\
8.35 \pm 4.70 \\
12.51 \pm 2.36\end{array}$ & $\begin{array}{l}110.94 \\
102.39 \\
106.35\end{array}$ \\
\hline ethyl tetradecanoate & $0.30 \pm 6.38$ & $\begin{array}{l}0.33 \\
0.50 \\
1.00\end{array}$ & $\begin{array}{l}0.59 \pm 5.15 \\
0.83 \pm 5.60 \\
1.22 \pm 3.30\end{array}$ & $\begin{array}{r}87.88 \\
106.00 \\
92.00\end{array}$ \\
\hline dodecanoic acid & $4.17 \pm 4.20$ & $\begin{array}{r}2.20 \\
5.40 \\
10.60\end{array}$ & $\begin{array}{r}6.51 \pm 3.40 \\
9.16 \pm 2.36 \\
15.75 \pm 6.40\end{array}$ & $\begin{array}{r}106.36 \\
92.41 \\
109.24\end{array}$ \\
\hline ethyl octanoate & $8.23 \pm 2.40$ & $\begin{array}{r}6.22 \\
10.15 \\
12.64\end{array}$ & $\begin{array}{l}13.97 \pm 1.46 \\
18.19 \pm 4.36 \\
21.54 \pm 3.40\end{array}$ & $\begin{array}{r}92.28 \\
98.13 \\
105.30\end{array}$ \\
\hline ethyl 3-methylbutanoate & $0.16 \pm 8.20$ & $\begin{array}{l}0.20 \\
0.40 \\
0.70\end{array}$ & $\begin{array}{l}0.33 \pm 6.40 \\
0.58 \pm 3.20 \\
0.83 \pm 4.60\end{array}$ & $\begin{array}{r}85.00 \\
105.00 \\
95.71\end{array}$ \\
\hline
\end{tabular}

due to its intense and pleasantly fruity odor (Nykanen and Suomalainen, 1983).

The evolution of ethyl esters of the $\mathrm{C}_{6}-\mathrm{C}_{12}$ monocar- boxylic acids during spirit aging was influenced by both factors studied, time and cider type; the hexanoic, octanoic, and decanoic ethyl esters decreased ( $\mathrm{P}=$ 
Table 2. Average Contents (Milligrams per Liter) of the Volatile Components of Distillates of Cider

\begin{tabular}{|c|c|c|c|c|c|}
\hline \multirow[b]{2}{*}{ compound } & \multirow[b]{2}{*}{ spirit } & \multicolumn{4}{|c|}{ age } \\
\hline & & $\begin{array}{c}0 \\
\text { months }\end{array}$ & $\begin{array}{c}3 \\
\text { months }\end{array}$ & $\begin{array}{c}6 \\
\text { months }\end{array}$ & $\begin{array}{c}9 \\
\text { months }\end{array}$ \\
\hline \multirow[t]{2}{*}{ ethyl 3-methylbutanoate } & $A$ & 0.00 & 0.06 & 0.07 & 0.09 \\
\hline & $\mathrm{B}$ & 0.00 & 0.00 & 0.05 & 0.06 \\
\hline \multirow[t]{2}{*}{ 3-methylbutyl ethanoate } & $A$ & 6.92 & 5.75 & 5.15 & 4.38 \\
\hline & $\mathrm{B}$ & 17.43 & 13.79 & 11.14 & 8.45 \\
\hline \multirow[t]{2}{*}{ ethyl hexanoate } & $A$ & 1.01 & 1.08 & 1.60 & 1.66 \\
\hline & $\mathrm{B}$ & 5.83 & 4.97 & 5.11 & 3.39 \\
\hline \multirow[t]{2}{*}{ 2- and 3-methyl-1-butanol } & $A$ & 828.01 & 737.62 & 747.73 & 793.07 \\
\hline & B & 727.24 & 655.33 & 579.45 & 570.52 \\
\hline \multirow[t]{2}{*}{ hexyl ethanoate } & $A$ & 1.00 & 0.81 & 0.71 & 0.59 \\
\hline & $\mathrm{B}$ & 0.13 & 0.11 & 0.09 & 0.06 \\
\hline \multirow[t]{2}{*}{ 1-hexanol } & $A$ & 49.86 & 48.83 & 49.60 & 51.30 \\
\hline & B & 2.15 & 3.22 & 3.67 & 4.05 \\
\hline \multirow[t]{2}{*}{ ethyl octanoate } & $A$ & 1.41 & 2.00 & 3.54 & 3.65 \\
\hline & B & 4.10 & 4.49 & 6.51 & 1.89 \\
\hline \multirow[t]{2}{*}{ 1-octanol } & $A$ & 0.11 & 0.14 & 0.17 & 0.16 \\
\hline & $\mathrm{B}$ & 0.17 & 0.18 & 0.16 & 0.19 \\
\hline \multirow[t]{2}{*}{ ethyl decanoate } & $A$ & 7.55 & 7.60 & 11.36 & 10.79 \\
\hline & $\mathrm{B}$ & 2.63 & 3.28 & 4.78 & 1.92 \\
\hline \multirow[t]{2}{*}{ diethyl butanedioate } & $A$ & 0.41 & 0.47 & 0.52 & 0.52 \\
\hline & $\mathrm{B}$ & 0.13 & 0.17 & 0.19 & 0.20 \\
\hline \multirow[t]{2}{*}{ 2-phenylethyl ethanoate } & $A$ & 21.45 & 17.60 & 14.37 & 12.62 \\
\hline & B & 2.11 & 1.74 & 1.35 & 1.26 \\
\hline \multirow[t]{2}{*}{ ethyl dodecanoate } & $A$ & 4.19 & 3.68 & 5.05 & 4.60 \\
\hline & $\mathrm{B}$ & 0.38 & 0.47 & 0.57 & 0.51 \\
\hline \multirow[t]{2}{*}{ ethyl tetradecanoate } & $A$ & 1.92 & 2.09 & 2.21 & 2.60 \\
\hline & $\mathrm{B}$ & 0.10 & 0.20 & 0.29 & 0.35 \\
\hline \multirow[t]{2}{*}{ octanoic acid } & $A$ & 14.78 & 14.82 & 14.16 & 16.54 \\
\hline & $\mathrm{B}$ & 38.80 & 49.56 & 31.69 & 28.44 \\
\hline \multirow[t]{2}{*}{ ethyl hexadecanoate } & $A$ & 1.24 & 1.76 & 5.38 & 3.36 \\
\hline & $\mathrm{B}$ & 0.07 & 0.78 & 1.12 & 1.31 \\
\hline \multirow[t]{2}{*}{ decanoic acid } & $A$ & 36.77 & 36.85 & 36.48 & 37.56 \\
\hline & $\mathrm{B}$ & 33.72 & 48.95 & 33.95 & 29.73 \\
\hline \multirow[t]{2}{*}{ dodecanoic acid } & $A$ & 10.66 & 10.63 & 10.55 & 7.89 \\
\hline & $\mathrm{B}$ & 3.10 & 3.08 & 3.15 & 2.34 \\
\hline \multirow[t]{2}{*}{ ethyl 9,12-octadecadienoate } & $A$ & 8.81 & 11.03 & 15.93 & 19.42 \\
\hline & $\mathrm{B}$ & 0.87 & 7.75 & 9.11 & 12.82 \\
\hline \multirow[t]{2}{*}{ tetradecanoic acid } & A & 5.49 & 4.67 & 4.69 & 4.52 \\
\hline & $B$ & 2.03 & 1.98 & 1.83 & 1.84 \\
\hline
\end{tabular}

$0.0001,0.0001$, and 0.0015 , respectively) during aging for cider manufactured from apple juice concentrate, although the concentration of these components increased in the case of the traditionally made cider. With regard to ethyl dodecanoate, a slight increase during aging was observed for all spirits studied $(P=0.0119)$; furthermore, an interactive effect between both factors studied was determined for this component $(P=0.0237)$.

The concentration of these esters ranged between 1.01 and $5.83 \mathrm{mg} / \mathrm{L}$ for ethyl hexanoate, between 1.41 and $6.51 \mathrm{mg} / \mathrm{L}$ for ethyl octanoate, between 1.92 and 11.36 $\mathrm{mg} / \mathrm{L}$ for ethyl decanoate, and between 0.38 and 5.05 $\mathrm{mg} / \mathrm{L}$ for ethyl dodecanoate; these results are slightly lower than those reported by De Smedt and Liddle (1975) for Calvados.

In the unaged spirits, ethyl esters of hexanoic and octanoic levels were higher in the spirits obtained from dider manufactured from apple juice concentrate, whereas ethyl esters of decanoic and dodecanoic concentrations were lower (Table 2).

The ethyl esters of long-chain fatty acids (tetradecanoic, hexadecanoic, and 9,12-octadecadienoic ethyl esters), bel onging to the heaviest aroma fraction, have different odor kinds such as vegetable oils and stearinelike; only ethyl hexadecanoate and ethyl 9,12-octadecadienoate showed significant evolution during aging $(P$ $=0.0018$ and 0.0001 , respectively), an increase of both compounds being detected.

On the other hand, significant differences were found between these components in both distilled cider types. The distillate obtained from traditional cider showed

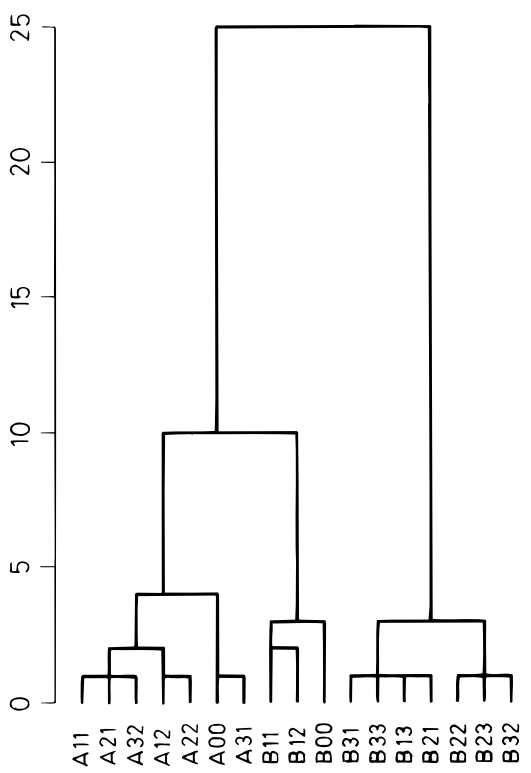

Figure 1. Dendogram. $A_{i j}$, spirit obtained from type $A$ cider; $B_{i j}$, spirit obtained from type $B$ cider; i, aging step; $j$, repetition number.

higher levels of these components than the distillate produced from the type B cider (Table 2 ).

The acetate esters studied, namely, 2-phenylethyl ethanoate, 3-methylbutyl ethanoate, and hexyl ethanoate, significantly decreased throughout aging $(P=$ 0.0001 for three acetate esters). In this sense, it is wellknown that ethanol acts as a nucleophilic reagent, and it displaces the other alcohol moiety by means of a transesterification mechanism. On the other hand, the acetate ester level in the distillate was cider-type dependent. Thus, we found more hexyl ethanoate and 2-phenylethyl ethanoate in the distillate produced from the type A than type B cider; however, less 3-methylbutyl ethanoate was determined in the distillate obtained from traditional cider (Table 2).

A significant increase in diethyl butanedioate level was detected during aging $(P=0.001)$. These results are in agreement with the fact that this ester is derived mostly from oak. Diethyl butanedioate occurred in the unaged spirits, which is due to metabolism of microorganisms (yeasts and bacteria) that develop during the fermentation process.

Likewise, various alcohols were monitored, namely, amyl, hexyl, and octyl alcohols. The evolution of 1-octanol during aging did not show statistical significance $(P=0.1583)$; however, 1-hexanol $(P=0.0128)$ and amyl alcohols $(P=0.0007)$ did. The concentration of 1-hexanol increased during aging, which may be a consequence of the transesterification process that the hexyl ethanoate carried out. This phenomenon was not observed in the case of amyl al cohols; probably, the loss by evaporation-diffusion (dependent on temperature) may be very significant for these alcohols. Higher amounts of amyl and hexyl alcohols were found in the distillate obtained from the traditional cider; the contrary occurred for 1-octanol (Table 2).

Four fatty acids were studied (octanoic, decanoic, dodecanoic, and tetradecanoic). Apart from ethanoic acid, octanoic and decanoic acids appear as the main compounds in the acid fraction. The concentration of dodecanoic and tetradecanoic acids significantly decreased during aging ( $\mathrm{P}=0.0001$ and 0.0001 , respectively). Except for octanoic acid, the highest fatty acid 


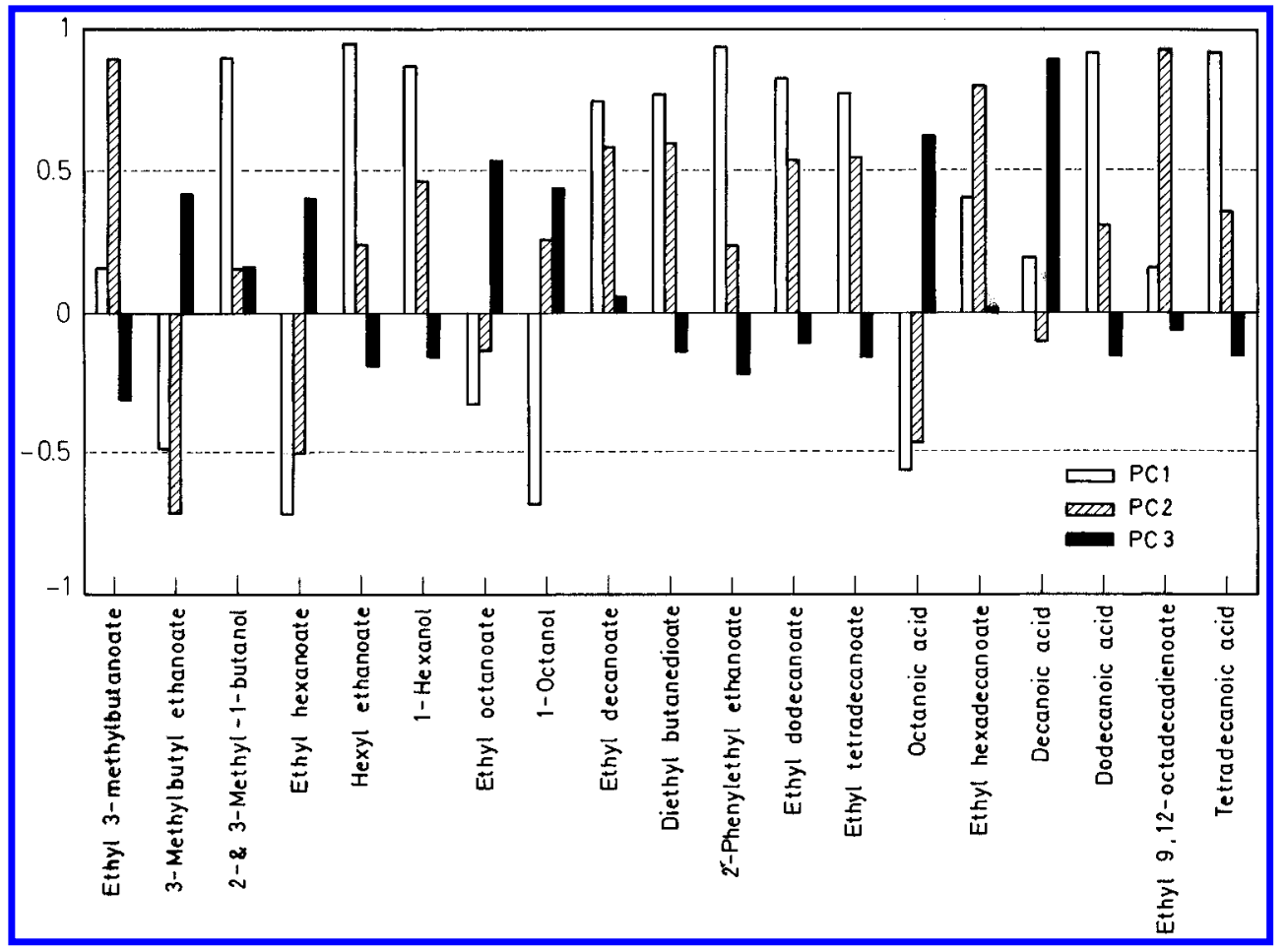

Figure 2. Loadings of volatile compounds on rotated principal components 1,2 , and 3 .

level was found in the distillate produced from the traditional cider.

Cluster Analysis. The aim of cluster analysis is to search for "natural" groupings among samples. An 17 $\times 17$ matrix consisting of squared Euclidian distances, where each observation was represented by 19-dimensional vectors, was employed for hierarchical cluster analysis of the data, using the average linkage method. The results of the cluster analysis are shown in Figure 1. As can be seen in the dendogram, two clusters were found above 10.0 in the rescaled distance: the first cluster consisted of the spirits made from the type B cider, which have a higher level maturation; on the other hand, the second cluster included the cider brandy obtained from traditional cider, without distinctions of aging level, as well as the distillates with less aging produced from the type B cider. However, three clusters were found bel ow $40 \%$ of the highest level of grouping, two with seven objects each and another with the remainder of the objects. At this grouping level, all of the spirits obtained from traditional cider are included in the same cluster, and the distillates (B) with less aging are grouped in another cluster.

Factor Analysis of the Internal Structure. An elevated number of high correlations among the variables studied, with high statistical significance, was obtained from the correlation matrix, and the determinant of the correlation matrix was found to be very low; thus, the data matrix could be consi dered adequate for factor analysis.

The number of principal components (PC) was determined from the correlation matrix, the data having previously been standardized. Three PCs that accounted for $89.2 \%$ of the variance were chosen on the basis of Kaiser's criterion (eigenvalues higher than 1.0 are chosen). The percentage of variance of each variable explained by the three factors considered (communality) was greater than $81 \%$ for $89.5 \%$ of the variables studied. On the other hand, the factorial model established could be appropriate for treating the data, taking into account the percentage of residuals determined (14\%) from reproduced correlation matrix with absolute values greater than 0.05 .

To ascertain the latent structure of the data, a Varimax rotation was carried out; the loadings of the first three varivectors obtained are shown in Figure 2.

As can be seen, the first varivector is closely related to long-chain fatty acids (tetradecanoic and dodecanoic), higher alcohols (amyl and hexyl alcohols), acetate esters (hexyl ethanoate and 2-phenylethyl ethanoate), ethyl esters of fatty acids of the middle aroma fraction (ethyl tetradecanoate, ethyl dodecanoate, and ethyl decanoate), and diethyl butanedioate, due to the high positive loadings; however, 1-octanol, ethyl hexanoate, and octanoic acid have high negative loadings for this varivector. Acids such as decanoic and octanoic are represented by the third varivector, and the second varivector corresponds to the ethyl esters of long-chain fatty acids (ethyl hexadecanoate and ethyl 9,12-octadecadi enoate), and ethyl 3-methylbutanoate; a high negative loading for 3-methylbutyl ethanoate was also obtained for this varivector.

A projection of the observations on the plane formed by the first two components (variance account for $80.5 \%$ ) is shown in Figure 3. As can be seen, the first component (eigenvector 1 ) allows us to differentiate between the spirits manufactured from different cider types, A and B, while the second component (eigenvector 2 ) is related to the aging time, especially when the distillates obtained from traditional cider were considered.

The scores for the first rotated component were higher in type A than type B spirits, and the spirits with more aging time had higher scores than the young spirits for the second rotated component (Figure 3 ). In consequence, the volatile compounds associated with the first principal component may be employed for classifying the spirits on the basis of the raw material, and the volatiles related to the second principal component may be used for determining the degree of aging.

Conclusion. The analytical method presented permits the determination of fatty acids, acetate esters, 


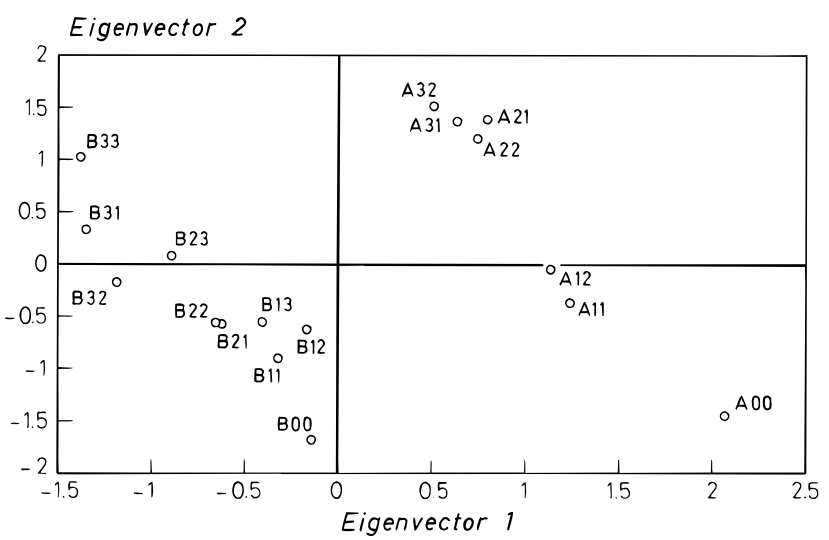

Figure 3. Eigenvector projection of spirits.

ethyl esters of fatty acids, and higher alcohols in distillates of ciders aged in oak wood with a good degree of reproducibility and accuracy.

During aging, the acetate esters and long-chain fatty acid levels decreased, whereas the concentrations of diethyl butanedioate, ethyl 3-methylbutanoate, ethyl esters of long-chain fatty acids, and 1-hexanol increased.

What is more, the spirits manufactured from cider obtained from traditional technology had higher concentrations of decanoic and dodecanoic ethyl esters and long-chain fatty acids than the distillates produced from cider obtained from apple juice concentrate.

From the monitoring of the variables studied (volatile components) in distillates of cider, "natural" groupings of spirits could be defined in relation to the raw material employed and the aging time.

\section{ACKNOWLEDGMENT}

We are grateful for the help from Dr. J uan F. Cacho and his collaborators in the optimization of the microextraction system.

\section{LITERATURE CITED}

Black, R.; Andreasen, A. Steroids in aged whisky. L. Assoc. Off. Anal. Chem. 1973, 56, 1357-1361.

De Smedt, P.; Liddle, P. The position of rum in the context of spirits in general. Ann. Technol. Aaric. 1975, 24, 269-286.

De Smedt, P.; Liddle, P. Identification in certain spirits of allyl alcohol (2-propen-1-ol) and compounds derived from it. Ind. Aliment. Agric. 1976, 93, 41-43.

De Smedt, P.; Liddle, P. I dentification of 1,1'-diethoxypropan2-one in spirits aged in wood. Am. I. Enol. Vitic. 1978, 29, 286-288.

Ferreira, V. New contributions to analytical chemistry of wine aroma. Ph.D. Dissertation, The University of Zaragoza (Spain), 1992.

Ferreira, V.; Rapp, A.; Cacho, J .; Hastrich, H.; Yavas, I. Fast and quantitative determination of wine flavor compounds using microextraction with freon 113. $\perp$. Agric. Food Chem. 1993, 41, 1413-1420.

Guymon, J . F.; Crowell, E. A. GC-separated brandy components derived from french and american oaks. Am. I. Enol. Vitic. 1972, 23, 114-120.
Hardy, P. Extraction and concentration of volatiles from dilute aqueous-alcoholic solution using trichlorofluoromethane. $L$. Agric. Food Chem. 1969, 17, 656-658.

Herraiz, M.; Reglero, G.; Herraiz, T.; Loyola, E. Analysis of wine distillates made from muscat grapes (Pisco) by multidimensional gas chromatography and mass spectrometry. L. Agric. Food Chem. 1990, 38, 1540-1543.

Lehtonen, M.; Suomalainen, H. Rhum. In Alcohol ic Beverages; Rose, A. H., Ed.; Academic Press: London, 1977; Chapter 9.

Liebich, H.; Koenig, W. A.; Bayer, E. Analysis of the flavor of rum by gas-liquid chromatography and mass spectrometry. L. Chromatogr. Sci. 1970, 8, 527-533.

Loyola, E.; Martín-Alvarez, P.; Herraiz, T.; Reglero, G.; Herraiz, M. A contribution to the study of the volatile fraction in distillates of wines made from muscat grapes (Pisco). Z. Lebensm. Unters. Forsch. 1990, 190, 501-505.

Marais, J.; Houtman, A. Quantitative gas chromatographic determination of specific esters and higher alcohols in wine using freon extraction. Am. J . Enol. Vitic. 1979, 250-252.

Nykanen, P.; Suomalainen, H. Odor thresholds and relative intensities of volatile aroma components in an artificial beverage imitating whisky. J . Food Sci. 1972, 394-398.

Nykanen, P.; Suomalainen, H. Esters of al iphatic monocarboxylic acids. In Aroma of Beer, Wineand Distilled Alcoholic Beverages; Nykanen, P., Suomalainen, H., Eds.; AkademieVerlag: Berlin, 1983; Chapter 11.

Onishi, M.; Guymon, J . F.; Crowell, E. A. Changes in some volatile constituents of brandy during aging. Am. I. Enol. Vitic. 1977, 28, 152-158.

Piggott, J .; Conner, J .; Clyne, J .; Paterson, A. The influence of non-volatile constituents on the extraction of ethyl esters from brandies. L. Sci. Food Aaric. 1992, 59, 477-482.

Reazin, G. Chemical mechanisms of whiskey maturation. Am. L. Enol. Vitic. 1981, 32, 283-289.

Reazin, G.; Baldwin, S.; Scales, H.; Washington, H.; Andreasen, A. Determination of the congeners produced from ethanol during whisky maturation. L. Assoc. Off. Anal. Chem. 1976, 59, 770-776.

SAS. AN OVA. In SAS/ STAT Guide for Personal Computers; J oyner, S. P., Ed.; SAS Institute: Cary, NC, 1985; Chapter 12.

SPSS. In SPSS-X User's Guide; McGraw-Hill, Ed.; SPSS: Chicago, IL, 1988.

Williams, P.; Strauss, C. 3,3-Diethoxybutan-2-one and 1,1,3 triethoxypropane: acetals in spirits distilled from Vitis vinifera grape wines. L. Sci. Food Aqric. 1975, 26, 11271136.

Woidich, H.; Pfannhauser, W.; Eberhardt, R. Results of gas chromatographic-mass spectrographic investigations of volatile components of apple brandies. Mitt. Klostern. 1978, 28, 56-23.

Yavas, I.; Rapp, A. Gas chromatographic-mass spectrometric investigation of raki flavor compounds. Dtsch. Lebensm. Rundsch. 1991, 87, 41-45.

Received for review April 24, 1995. Revised manuscript received September 28, 1995. Accepted October 13, $1995 .{ }^{\otimes}$ This work was financially supported by FICYT and the Principado de Asturias.

\section{J F950244G}

${ }^{\otimes}$ Abstract published in Advance ACS Abstracts, December 1, 1995. 